\title{
Cerebrovascular Accident Following MDMA Ingestion
}

\author{
C. D. Muntan, $M D^{\mathrm{a}}$, V. Tuckler, $M D^{\mathrm{a}}$ \\ a LSUHSC Charity Hospital: Section of Emergency Medicine, NO, LA
}

\section{INTRODUCTION}

Cerebrovascular accident (CVA) is the third leading cause of death in the United States. The annual incidence is 700,000, with a mortality of $20 \%$ in the first year [1-2]. Cerebrovascular accident in relation to 3,4-methylenedioxymethamphetamine (MDMA, ecstasy) is rare and not much is known about the pathophysiology [3-4].

The Drug Abuse Warning Network (DAWN) is a surveillance system that follows drug related visits to emergency departments (ED) throughout the United States. Several recent reports focused on drugs (such as methamphetamine, LSD, GHB, ketamine, and MDMA) commonly used at clubs and raves [5-7]. The DAWN System reported that ED visits for MDMA rose from 253 in 1990 to 2,850 in 1999. The report also stated that most ED visits secondary to MDMA use included multiple drug intoxication, and the majority of users were between the ages of 18 and 25 [5]. Updated reports from DAWN showed that ED visits for MDMA dramatically increased from 2,850 to 5,542 between 1999 and 2001 before stabilizing between 2001 and 2002 [6-7].

The National Institute on Drug Abuse's Community Epidemiology Workgroup (CEWG) recently reported that the use of MDMA has spread from the clubs to urban and rural areas. In 2003 reports from Texas, Illinois and New York, it appears that young whites are not the only group using these "club drugs" [8].

\section{CASE REPORT}

A 20-year-old African American male, behaving strangely, arrived at the ED. The patient's brother witnessed the patient drinking beer, smoking marijuana (THC) and ingesting MDMA prior to performing at a rap concert. During the concert, the patient suddenly stopped rapping, was taken back stage, started vomiting and became aphasic. An hour later, he was taken to the ED.

The patient arrived at the ED awake; he was non-verbal, but he did follow verbal instructions. An initial physical examination included blood pressure: 142/57, pulse: 98 , respiratory rate: 20 , pulse oximetry: $98 \%$ on room air and a temperature of: 37.1. There were no signs of trauma. His strength was $5+/ 5$ bilaterally in the upper and lower extremities but otherwise difficult to examine because of his extremely combative nature. There were no external signs of trauma and no facial droop. His pupils were $4 \mathrm{~mm}$, equal, round and bilaterally reactive. Extra ocular movements were intact via tracking. Oropharnyx was clear, and his neck was supple with full range of motion. Cardiac examination showed regular rhythm without murmur or gallops. The lungs were bilaterally clear to auscultation. The abdomen was soft, non-distended, non-tender, and bowel sounds were present. His pulses were +2 bilaterally.

Laboratory values showed a glucose level of $126 \mathrm{mg} / \mathrm{dl}$. His white blood cell count was 13,800 per microliter with no shift or bands. Serum chemistry panel, urinalysis, and sedimentation rate were within normal limits. Aspirin and acetaminophen levels were undetectable. The CPK level was 692 units/liter. His ethanol level was $113 \mathrm{mg} / \mathrm{dl}$. A urine drug screen was negative for phencyclidine, barbiturates, benzodiazepines, opiates, cocaine and amphetamines. But the screen was positive for THC-20 and confirmed as cannabinoid. Computed tomography (CT) of the head was negative. The patient was reexamined numerous times and showed no focal neurological deficits. He remained non-verbal but continued to move all extremities. A lumbar puncture was performed. Clear fluid was obtained and the opening pressure was $140 \mathrm{~mm} \mathrm{H}_{2} \mathrm{O}$. Results showed a WBC of 0 per microliter, a RBC of 42 per microliter, a glucose of $67 \mathrm{mg} / \mathrm{dl}$ and a total protein of $47 \mathrm{mg} / \mathrm{dl}$.

Approximately 18 hours after the reported ingestion, the patient developed new right-sided weakness, left-sided facial droop and bilateral hyperreflexia in the lower extremities. A magnetic resonance image (MRI) of the brain showed left middle cerebral artery complete infarction (Figure). A carotid ultrasound showed no significant stenosis, and a transesophageal echocardiogram was normal. A magnetic resonance angiogram (MRA) of the 


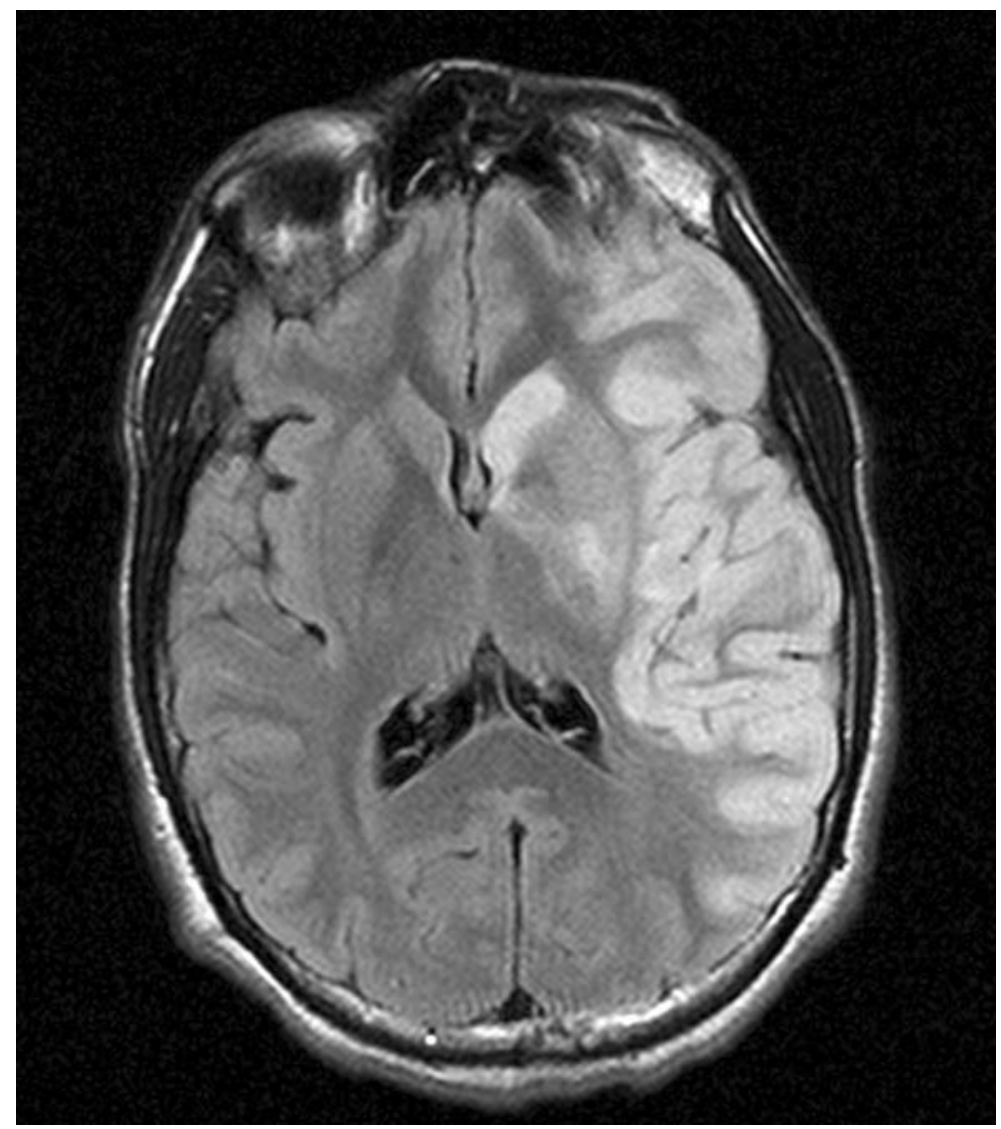

Figure 1. MRI of the patient's brain with complete left middle cerebral artery infarction.

brain showed mild to moderate stenosis of the distal left internal carotid artery. His sickle cell, anti-nuclear antibody, homocysteine, and coagulation studies were negative. A cerebrospinal fluid culture grew no organisms. The patient was transferred to a rehabilitation facility with residual right-sided weakness and no confirmed etiology for the CVA.

\section{DISCUSSION}

Methylenedioxymethamphetamine can emerge as a serious toxidrome: commonly including tachycardia, hypertension, mydriasis, agitation, bruxism, dry mouth and seizures [1]. Fatal complications include acute renal failure, hyponatremia from water intoxication/SIADH, rhabdomyolysis, serotonin syndrome, hepatic failure, disseminated intravascular coagulation and cardiovascular collapse [9-10]. Most texts only mention the possibility of CVA from MDMA but suggest vasospasm as a mechanism [1].

It is known that MDMA causes massive release of serotonin into synapses that produces euphoric sensations. However, in response to this massive release, there is a down-regulation of serotonin receptors. An article from the Netherlands suggests that low cortical 5-HT2 (serotonin) receptor densities are significantly associated with low cerebral blood vessel volumes. This implies a vasoconstriction and an increased risk for stroke [2]. Similarly, a case report from the United Kingdom identified a 35-year-old male who showed hemiparesis and dysphasia 36 hours after MDMA use. CT of the head showed extensive acute left cerebral infarction. An angiogram showed left middle cerebral artery occlusion, and the authors proposed an association between MDMA and CVA [3]. An article from the United States discusses a cerebral vasoconstriction syndrome in relation to serotonergic drug ingestion. Three patients ingested different combinations of sertraline, paroxetine, clonazepam, trazodone, sumatriptan and dextromethorphan, and each had an ischemic stroke secondary to vasoconstriction [11].

\section{CASE CONCLUSION}

In this case report, a 20-year-old man suffered a stroke in temporal association with marijuana and MDMA use. Even though a drug screen did not confirm the presence of MDMA, the patient had a thorough workup that was negative; however, the patient's brother reportedly witnessed the MDMA ingestion.

Unfortunately, data from the DAWN reports have repeatedly confirmed that the use of MDMA is on the rise in the United States, and recent CEWG reports suggest that the location of use and the ethnicity of users are drastically changing. Physicians 
must be aware of the numerous presentations possible with MDMA and include CVA in the differential diagnosis with any drug ingestion.

\section{REFERENCES}

1. Scott PA, Barsan WG. Stroke, Transient Ischemic Attack, and other Central Focal Conditions. In: Tintinalli JE, Kelen, GD, Stapczynski JS editors. Emergency Medicine: A Comprehensive Study Guide, (5th ed.). New York: McGraw-Hill Companies, Inc; 2000; 1430, pp. 1118-19.

2. National Center for Health Statistics. Health. United States. 2001. Hyattsville, Md. Public Health Service. 2001; Available from: http://www.cdc.gov/nchs/

3. Reneman L, Habraken JBA, Majoie CBL, Booij J, den Heeten GJ. MDMA and its association with cerebrovascular accidents: preliminary findings. Am J Neuroradiol. 2000; 21(6):1001-7.

4. Manchanda S. Connolly MJ. Cerebral infarction in association with Ecstasy abuse. Postgrad Med Jour. 1993; 69(817): 874-5.

5. The DAWN Report. Club Drugs. Office of Applied Studies, Substance Abuse and Mental Health Services Administration.
December 2000; Available from: http://dawninfo.samhsa.gov/ old_dawn/pubs_94_02/shortreports/files/clubdrug.pdf

6. The DAWN Report. Club Drugs, 2001 Update. Office of Applied Studies, Substance Abuse and Mental Health Services Administration. October 2002. Available from: http://dawninfo .samhsa.gov/old_dawn/pubs_94_02/shortreports/files/ DAWN_tdr_club_drugs02.pdf

7. Gauvin, DV. Recent drug use trends in the U.S: The challenge to the emergency department. Lecture presented at AAEM National Scientific Meeting, February 22, 2003; New Orleans, LA.

8. The National Institute on Drug Abuse. Research Report Series-MDMA Abuse (Ecstasy). February 2005; Available from: http://www.drugabuse.gov/ResearchReports/MDMA/MDMA3 .html\#who

9. Dowling GP, McDonough ET, Bost, RO. Eve and ecstasy: A report of five deaths associated with the use of MDEA and MDMA. JAMA. 1987; 257:1615-7.

10. Henry JA, Jefferys KJ, Dawlings S. Toxicity and deaths from 3,4 methylenedioxymethamphetamine ("ecstasy"). Lancet. 1992; 340:384-7.

11. Singhal AB, Caviness VS, Begleiter AF, Mark EJ, Rordorf G, Koroshetz WJ. Cerebral vasoconstriction and stroke after use of serotonergic drugs. Neurology. 2002; 58:130-33. 